\title{
MxA Overexpression Reveals a Common Genetic Link in Four Fanconi Anemia Complementation Groups
}

\author{
Youlin Li and Hagop Youssoufian \\ Department of Medicine, Hematology-Oncology Division, Brigham and Women's Hospital, Harvard Medical School, Boston, \\ Massachusetts 02115
}

\begin{abstract}
Fanconi anemia (FA) consists of a group of at least five autosomal recessive disorders that share both clinical (e.g., birth defects and hematopoietic failure) and cellular (e.g., sensitivity to cross-linking agents and predisposition to apoptosis) features with each other. However, a common pathogenetic link among these groups has not been established. To identify genetic pathways that are altered in FA and characterize shared molecular defects, we used mRNA differential display to isolate genes that have altered expression patterns in FA cells. Here, we report that the expression of an interferon-inducible gene, $M x A$, is highly upregulated in cells of FA complementation groups $\mathrm{A}, \mathrm{B}, \mathrm{C}$, and $\mathrm{D}$, but it is suppressed in FA group $C$ cells complemented with wild-type $F A C$ cDNA as well as in non-FA cells. A posttranscriptional mechanism rather than transcriptional induction appears to account for MxA overexpression. Forced expression of MxA in Hep3B cells enhances their sensitivity to mitomycin $\mathrm{C}$ and induces apoptosis, similar to the FA phenotype. Thus, MxA is a downstream target of FAC and is the first genetic marker to be identified among multiple FA complementation groups. These data suggest that FA subtypes converge onto a final common pathway, which is intimately related to the interferon signaling mechanism. Constitutive activity of this pathway may explain a number of the phenotypic features of FA, particularly the pathogenesis of bone marrow failure. (J. Clin. Invest. 1997. 100:28732880.) Key words: apoptosis • cross-linker • differential display $\bullet$ gene regulation $\bullet$ interferon
\end{abstract}

\section{Introduction}

Phenotypic manifestations of Fanconi anemia (FA) ${ }^{1}$ include skeletal and visceral malformations, predisposition to cancer, and progression to bone marrow failure and acute leukemia (1-3). A pathognomonic finding in FA cells is the presence of

H. Youssoufian's present address is Department of Molecular and Human Genetics, Baylor College of Medicine, Houston, Texas 77030.

Address correspondence to Hagop Youssoufian, M.D., Department of Molecular and Human Genetics, Baylor College of Medicine, One Baylor Plaza, Houston, TX 77030. Phone: 713-798-8311; FAX: 713-798-5386.

Received for publication 24 June 1997 and accepted in revised form 26 September 1997.

J. Clin. Invest.

(C) The American Society for Clinical Investigation, Inc. 0021-9738/97/12/2873/08 \$2.00

Volume 100, Number 11, December 1997, 2873-2880

http://www.jci.org spontaneous chromosomal gaps and breaks and their accentuation by bifunctional alkylating agents (cross-linkers), such as mitomycin C (MMC). Somatic cell hybrid studies have identified at least five distinct complementation groups of FA (4-6), and the genes mutant in groups $\mathrm{A}, \mathrm{C}$, and $\mathrm{D}$ have been mapped to chromosomes $16 \mathrm{q}, 9 \mathrm{q}$, and $3 \mathrm{p}$, respectively $(5,7,8)$. Furthermore, the genes for complementation groups $\mathrm{A}$ ( $F A A$; reference 9) and $\mathrm{C}(F A C$; references 10 and 11$)$ have been cloned, and despite their ability to suppress MMC cytotoxicity in cells of appropriate FA complementation groups, these genes and their protein products share little sequence homology with each other or with any other known genes or proteins.

We and others have been investigating the subcellular location and biochemical interactions of FA gene products in order to understand their function. FAC is a $63-\mathrm{kD}$ cytoplasmic protein $(12,13)$ that is thought to function as a biological sensor and prevent or attenuate DNA damage (14). FAC has been shown to interact with at least three cytoplasmic proteins in vitro (15), suggesting that it is a component of a multimeric complex. One of the interacting proteins is NADPH cytochrome $\mathrm{P}-450$ reductase, a microsomal enzyme involved in xenobiotic metabolism (Youssoufian, H., T. Hoshino, J.M. Liu, P. Joseph, and A.K. Jaiswal, manuscript submitted for publication); FAC suppresses the catalytic activity of this reductase. By contrast, much less is known about the localization and function of FAA. It is considerably larger than FAC with a predicted molecular mass of $163 \mathrm{kD}$ and contains both a putative nuclear localization signal and an imperfect leucine zipper. Thus, FAA may function within the nucleus in a manner distinct from FAC.

To understand the molecular pathogenesis of FA in the context of its genetic heterogeneity, we used mRNA differential display analysis (16) to characterize genetic alterations in FA cells. Here we report that the expression of an IFN-inducible gene, $M x A$ (17-19), is highly upregulated in cells of multiple FA complementation groups. In addition, wild-type FAC can suppress the expression of MxA in lymphoblastoid cells from FA complementation group $\mathrm{C}(\mathrm{FA}-\mathrm{C})$ and restore resistance to MMC. MxA is a GTPase (20) that belongs to the Mx family of proteins, which are ubiquitous in eukaryotes (21-25) and mediate a number of fundamental cellular processes, including resistance to certain viral infections in mice and humans (26-30) and vacuolar sorting in Saccharomyces cerevisiae (25). Our results suggest that the activities of at least four distinct FA genes converge onto a common genetic pathway, which is intimately related to IFN signaling and susceptibility to apoptosis.

1. Abbreviations used in this paper: FA, Fanconi anemia; FA-C, Fanconi anemia complementation group $\mathrm{C}$; FAC, protein defective in FA-C; MMC, mitomycin C; TUNEL, terminal transferase-mediated UTP nick end-labeling. 


\section{Methods}

Cell culture. Epstein-Barr virus-transformed human lymphoblastoid cell lines were maintained in RPMI 1640 (GIBCO BRL, Gaithersburg, MD) and $15 \%$ FBS. In addition, stably transfected FA-C lymphoblastoid cells HSC536-Vect (transfected with the empty DRA-CD vector) and HSC536-FAC (transfected with DRA-FAC) described previously (15) were supplemented with $200 \mu \mathrm{g} / \mathrm{ml}$ hygromycin B (Boehringer Mannheim Biochemicals, Indianapolis, IN). Other FA cell lines used were HSC99 (FA-A; reference 5), HSC230 (FA-B; reference 5), RA568 (FA-C; reference 15), and HSC230 and PD-20 (FA-D; references 5 and 8 ). Non-FA hematopoietic cells were grown in RPMI 1640-10\% FBS. COS-1 and Hep3B cells were grown in Dulbecco's modified essential medium (DMEM) and 10\% FBS. Primary human fibroblasts (GM02149; American Tissue Type Collection, Rockville, MD) were grown in DMEM-20\% FBS and supplemented with vitamins as well as essential and nonessential amino acids. All cells were cultured at $37^{\circ} \mathrm{C}$ in a humidified atmosphere containing $5 \% \mathrm{CO}_{2}$.

Expression plasmids. Full-length human $F A C$ cDNA cloned into the mammalian episomal expression vector DRA-CD has been described previously (15). p78/2-8B containing the full-length coding sequence of MxA (19) was obtained from the American Tissue Type Collection. Wild-type FAC, a mutant FAC allele (L554P), and fulllength MxA were also cloned into pcDNA3 (Invitrogen Corp., San Diego, CA) for expression in COS-1 and Hep3B cells. pXP2-MxA809 was constructed by inserting a PCR-amplified 809-bp genomic fragment of the MxA promoter (19) into the KpnI and BglII sites of the promoterless luciferase reporter plasmid pXP2 (gift of Dr. D. Tenen, Beth Israel Hospital, Boston, MA).

Antibodies. The generation of anti-FAC antiserum has been described previously (13-15). An aliquot of goat polyclonal anti-human MxA antibodies was kindly provided by Dr. M.A. Horisberger (CibaGeigy Ltd., Basel, Switzerland) and anti-MxA rabbit polyclonal antibodies were subsequently generated by us against a $30-\mathrm{kD}$ histidinetagged fusion protein (MxA amino acids 241-499). Other antisera used in this study were obtained from commercial sources and included anti-human STAT1 p84/p91, STAT2 p113, and STAT3 p92 (Santa Cruz Biotechnology Inc., Santa Cruz, CA), anti-human IP10 (PeproTech, Inc., Rocky Hill, NJ), anti-human- $\beta_{2}$-microglobulin and anti-human HLA class I antigen (Sigma Chemical Co., St. Louis, $\mathrm{MO}$ ), and anti- $\beta$-tubulin (Boehringer Mannheim Biochemicals).

$m R N A$ differential display. $0.5 \mu \mathrm{g}$ of total RNA treated with RNase-free DNase I was reverse transcribed and the cDNAs were amplified by PCR using one base-anchored oligo-dT primers (GenHunter Corporation, Nashville, TN; reference 16) in the presence of $\left[\alpha^{35}\right.$ S]dATP. The PCR products were resolved on $6 \%$ urea-polyacrylamide sequencing gels. Differentially expressed bands were cut from gels, reamplified for 30 cycles, cloned into the vector pCR2.1 (Invitrogen Corp.), and sequenced. Reamplified cDNAs were also labeled with $\left[\alpha^{32} \mathrm{P}\right] \mathrm{dCTP}$ by random-prime labeling (Boehringer Mannheim Biochemicals) and used as hybridization probes in Northern analyses.

Northern analysis. Total RNA or poly A-selected mRNA isolated by previously described methods (31) was fractionated on $1 \%$ agarose gels containing formaldehyde, transferred to Biotrans nylon membranes (ICN Biomedicals, Inc., Irvine, CA), and fixed by baking at $80^{\circ} \mathrm{C}$ for $30 \mathrm{~min}$. Prehybridization and hybridization were performed according to the manufacturers' suggestions in a buffer containing $50 \%$ formamide. Final washing was in $0.1 \times$ SSC and $0.1 \%$ $\mathrm{SDS}$ at $55^{\circ} \mathrm{C}$ for $30 \mathrm{~min}$

Western analysis. For Western (or immunoblotting) experiments, total cell lysates or immune complexes obtained by immunoprecipitation of cytosolic lysates were resolved by SDS-PAGE and transferred to polyvinyldifluoride membranes (DuPont-Merck Pharmaceutical Co., Wilmington, DE). After blocking, membranes were reacted sequentially with a primary antibody followed by horseradish peroxidase-conjugated secondary antibodies (GIBCO BRL) and visualized by chemiluminescence (DuPont-Merck Pharmaceutical Co.).
Transfections. COS- 1 cells were grown to $\sim 50 \%$ confluence in $10-\mathrm{cm}$ dishes and transfected transiently with $1 \mu \mathrm{g} / \mathrm{ml}$ plasmid DNA by the DEAE-dextran as described previously (13), while Hep3B cells were stably transfected using a calcium phosphate coprecipitation method. Stable Hep3B transfectants were selected in the presence of G418 $(400 \mu \mathrm{g} / \mathrm{ml})$.

Nuclear run-on assay. Nuclei were isolated by sucrose gradient centrifugation, and in vitro transcription was performed as described (31). $\left[\alpha^{32} \mathrm{P}\right] \mathrm{UTP}-$ labeled transcripts were isolated as described (32), and $6.3 \times 10^{5} \mathrm{cpm} / \mathrm{ml}$ was used to probe identical strips of Hybond$\mathrm{N}^{+}$(Amersham Life Sciences-USB, Arlington Heights, IL) filters containing $10 \mu \mathrm{g}$ of linearized plasmid DNA. Hybridization and washing conditions were similar to the Northern blots.

Promoter analysis. Lysates from COS-1 cells transfected with promoter and reporter vectors were prepared using the Luciferase Assay System (Promega Corp., Madison, WI), and luciferase activity was measured with a luminometer. To control for the efficiency of transfection, 100- $\mu \mathrm{l}$ aliquots of lysates were also incubated with 3.5 $\mathrm{mM} O$-nitrophenyl- $\beta$-D-galactopyranoside (Sigma Chemical Co.) at $37^{\circ} \mathrm{C}$ for $30 \mathrm{~min}$ and the activity of $\beta$-galactosidase was assessed by light absorbance measured at $420 \mathrm{~nm}$.

Determination of cell survival in response to $M M C$. Cell survival in response to MMC (Sigma Chemical Co.) was performed by incubation of $1 \times 10^{4}$ viable cells with different concentrations of MMC for $6 \mathrm{~d}$ and counting of live cells by trypan blue exclusion. Data obtained from at least three independent experiments are shown.

Apoptosis assays. Two different assays were used for the detection of apoptotic cells in Hep3B cells overexpressing MxA. First, coverslips containing transfected Hep3B cells were fixed with $3.5 \%$ paraformaldehyde for $30 \mathrm{~min}$, and the terminal transferase-mediated UTP nick end-labeling (TUNEL) assay was performed using terminal transferase and fluorescein-conjugated dUTP (Boehringer Mannheim Biochemicals). Apoptotic cells were visualized by fluorescence microscopy, and fluorescent cells in five different fields on each coverslips were counted. Second, genomic DNA enriched for small fragments was isolated from parental and MxA-expressing cells using a modification of the Hirt procedure. Briefly, Hep3B cells were washed with PBS containing $\mathrm{Ca}^{2+} / \mathrm{Mg}^{2+}$, detached by scraping, and resuspended in a buffer containing $10 \mathrm{mM}$ Tris- $\mathrm{HCl}(\mathrm{pH} 8.0), 10 \mathrm{mM}$ EDTA, $20 \mu \mathrm{g} / \mathrm{ml} \mathrm{RNase} \mathrm{A,} \mathrm{and} 0.6 \%$ SDS. After $15 \mathrm{~min}$ at $37^{\circ} \mathrm{C}$, $\mathrm{NaCl}$ was added to a final concentration of $1.2 \mathrm{M}$ and the mixture was precipitated overnight at $4^{\circ} \mathrm{C}$. After spinning in a microcentrifuge for $5 \mathrm{~min}$, the supernatant was extracted with phenol and chloroform, precipitated with $2 \mathrm{vol}$ of ethanol, resuspended in TE buffer, and resolved on $2 \%$ agarose gel in Tris-acetate buffer.

\section{Results}

MxA gene is overexpressed in FA-C cells. Approximately $20 \%$ of the total cellular RNA from HSC536 and HSC536-FAC cells was analyzed by mRNA differential display. As demonstrated previously (15), electroporation with the episomal vector DRA-FAC and stable expression of FAC in HSC536 cells restores their resistance to MMC. Thus, any differentially expressed product may correlate with the cellular phenotype of MMC sensitivity. Using primers HT11 C and HAP12 (GenHunter kit 2), we detected a 340-bp fragment that was uniquely expressed in HSC536 but not FAC-complemented cells (Fig. 1). Cloning of this fragment and partial sequencing showed a high degree of identity with nucleotides 2529-2784 of the human $M x A$ cDNA (also called p78; reference 19). The differential expression of MxA mRNA from HSC536 was further investigated by Northern hybridization using a ${ }^{32} \mathrm{P}$-labeled 1-kb PstI fragment obtained from the full-length cDNA clone p78/2-8B as a probe. In agreement with the previously reported size of $\mathrm{MxA}$, a $2.8-\mathrm{kb}$ band was detected in lanes con- 


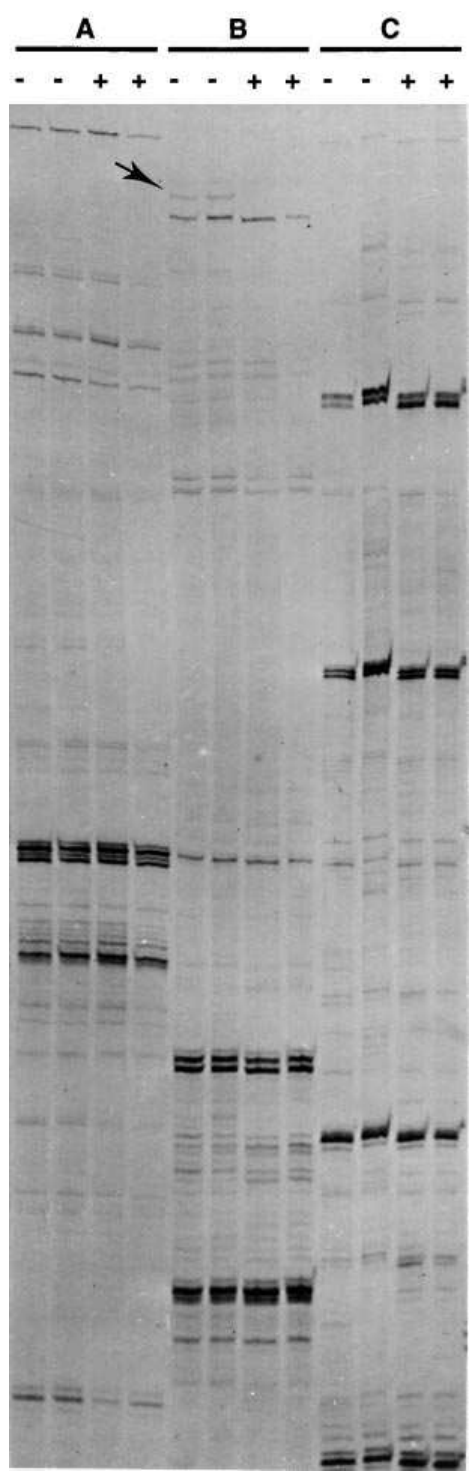

Figure 1. mRNA differential display analysis in FA-C cells. Total cellular RNA from HSC536 and HSC536FAC cells was analyzed by mRNA differential display. To minimize artifacts, two independent reversetranscribed reaction products from HSC536 (-) and HSC536-FAC (+) HSC536 cells were used for subsequent PCR amplifications. Results obtained with three different primer pairs $(A, B$, and $C)$ are shown. Primers HT11 C and HAP12 (GenHunter RNA image kit 2) were used to obtain the display pattern in panel B. A 340bp corresponding to a partial cDNA clone of MxA from the $3^{\prime}$ end is shown (arrow). taining RNA from parental and vector-transfected HSC536 cells but not from FAC-transfected cells (Fig. $2 A$ ). Six other differentially-displayed bands showed no consistent differences in their expression patterns by Northern analysis and were not analyzed further (data not shown).

Altered expression of MxA but not other IFN-induced proteins. Consistent with the differential expression of mRNA, MxA protein expression was also detected in parental and vector-transfected HSC536 cells, but not in FAC-transfected cells (Fig. $2 \mathrm{~B}$ ). To assess the possibility that the expression of other IFN-inducible genes and STATs that transduce IFN signals are also altered in FA, we performed immunoblotting experiments with antibodies directed against HLA class I (Fig. 2 B) as well as $\beta_{2}$-microglobulin and the $\gamma$-IFN-inducible gene IP10 (data not shown). Both HLA class I antigen and $\beta_{2}$-microglobulin were expressed in noncomplemented and complemented FA-C cells in approximately equal levels, while IP-10 expression was absent from both cell types. The expression of STAT1 (Fig. 2 B), STAT2, and STAT3 (data not shown) were similar in the three cell types. In addition, we also noted no variations in the expression of $\alpha$ - and $\gamma$-IFN or their receptors in HSC536 parental and FAC-complemented cells, as assessed by reverse-transcription and PCR (data not shown). Therefore, while we cannot exclude completely an altered expression pattern for other genes involved in IFN-mediated signaling, our data demonstrate that the IFN-inducible pathway is not globally dysregulated in FA-C cells.

$M x A$ is also overexpressed in FA groups $A, B$, and $D$. We also assessed the expression of MxA in a larger panel of FA and non-FA cells by Northern (Fig. $3 A$ ) and Western (Fig. 3 $B)$ analyses. MxA expression was upregulated in additional FA-C cells that contain different $F A C$ gene mutations as well as in other well-defined FA cells that belong to complementation groups A, B, and D. By contrast, we did not detect MxA overexpression in a number of non-FA cells, either hematopoietic or nonhematopoietic. Likewise, MxA was suppressed in the non-FA lymphoblastoid cell line LCL171 (15) and in Nalm6 cells (data not shown). These results confirm previous studies (33) that the expression of MxA is generally silent in most established tissue culture lines and primary cell types. Importantly, we demonstrate that MxA overexpression is a cellular phenotype that is shared by at least four different FA complementation groups.

Accumulation of MxA mRNA in FA-C cells is mainly posttranscriptional. Both transcriptional and posttranscriptional mechanisms may be responsible for the observed differences in the steady-state levels of MxA mRNA. To estimate the relative transcription rates of MxA and assess whether the differ-

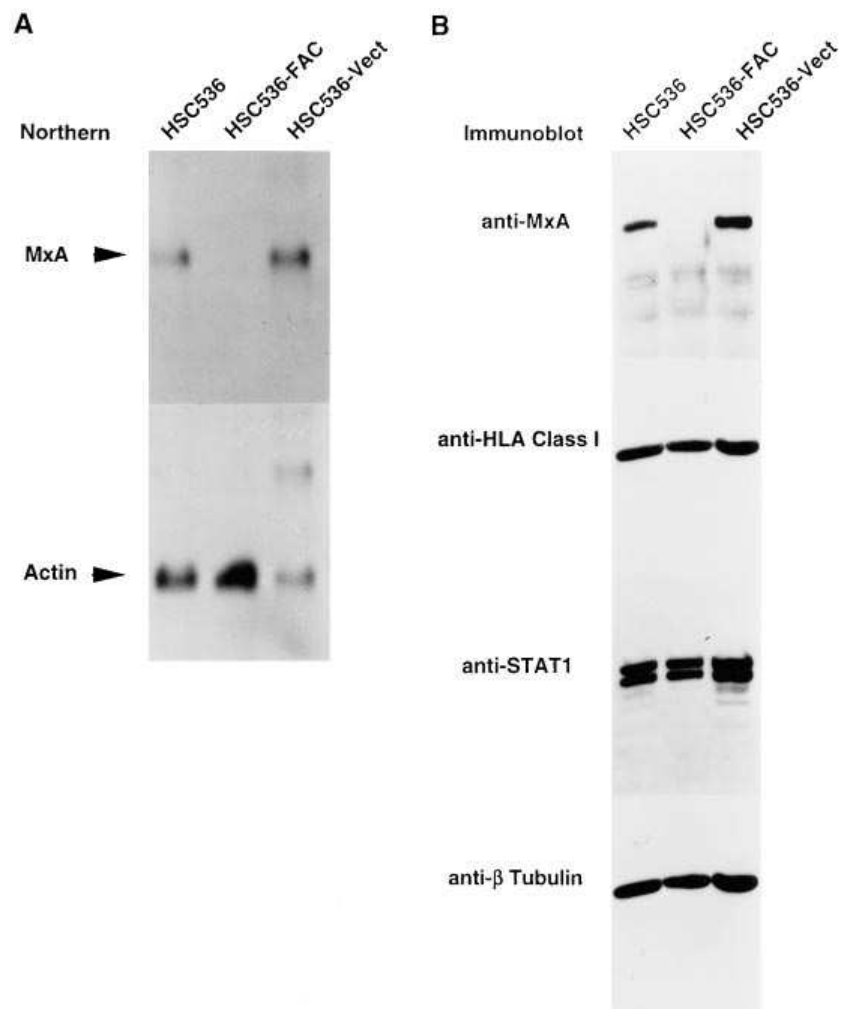

Figure 2. Differential expression of MxA but not other IFN-inducible genes in FA-C cells. $(A)$ Northern analysis of total RNA probed for MxA expression and for $\beta$-actin as loading control. (B) Immunoblot of lysates from the same panel of cell lines probed with the indicated antisera. $\beta$-tubulin expression is used for loading control. 
A

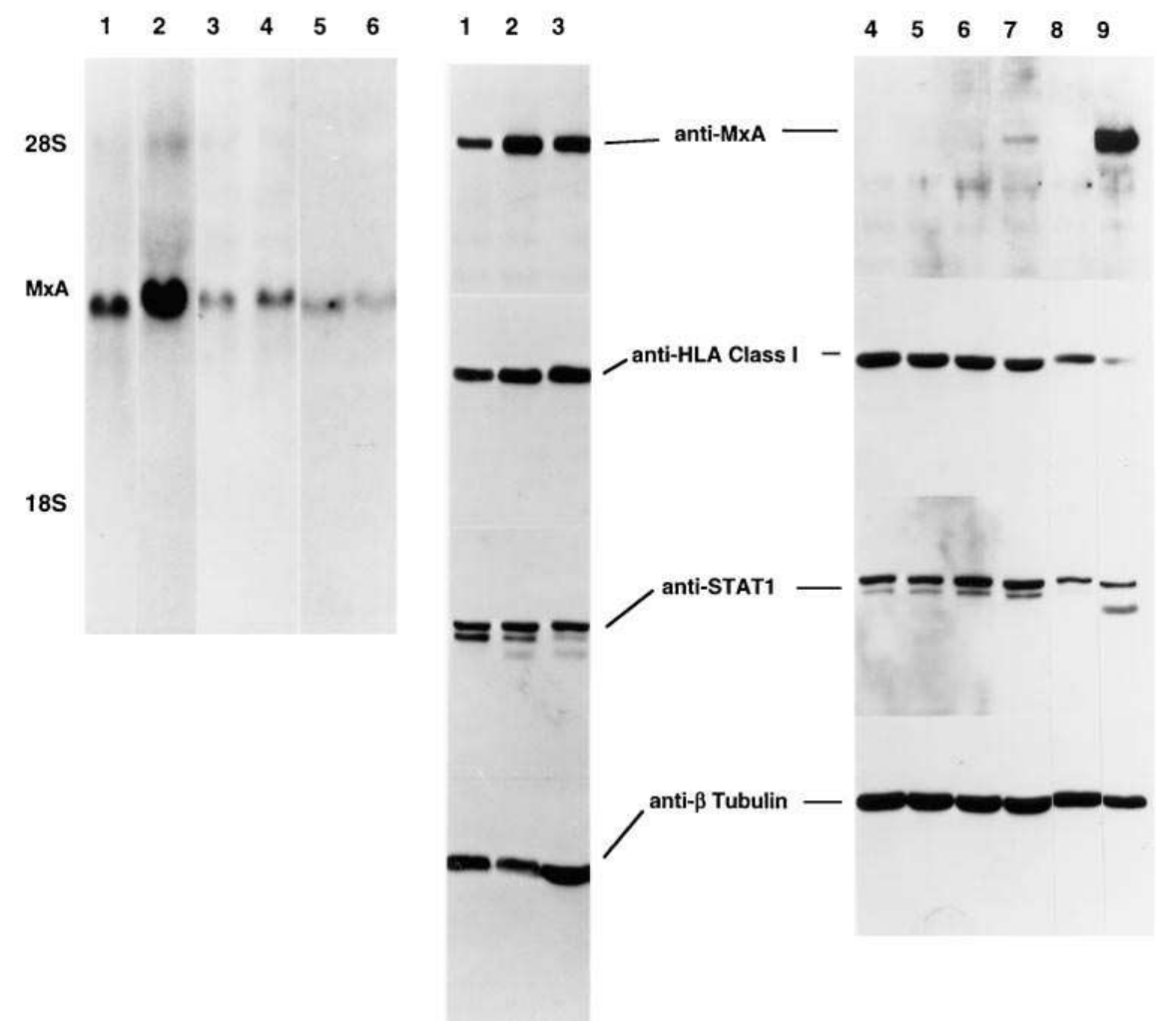

Figure 3. Expression of MxA in FA and non-FA cells. $(A)$ Northern analysis of total RNA from the following FA cells: HSC99 (FA-A, lane 1), HSC230 (FA-B, lane 2), RA568 (FA-C, lane 3), GM4510 (FA-C, lane 4), PD-20 (FA-D, lane 5), and HSC62 (FA-D, lane 6). The positions of MxA, 28S rRNA and 18S rRNA are shown. (B) Immunoblot of lysates from the following cells probed with the indicated antisera: HSC99 (FA-A, lane 1), HSC230 (FA-B, lane 2), PD-20 (FA-D, lane 3), GM02149 (primary human fibroblast, lane 4), K563 (myeloid/monocytic cell line, lane 5), Hep3B (human hepatoma cell line, lane 6) Hep3B cells stably transfected with pcDNA3-MxA (lane 7), COS-1 (monkey kidney cell line, lane 8 ), and COS-1 cells transfected with pcDNA3-MxA (lane 9). ential accumulation of $M x A$ mRNA is regulated by transcriptional or posttranscriptional mechanisms, we performed in vitro transcription on isolated nuclei from HSC536-Vect and HSC536-FAC cells by radiolabeling of RNA and using it as a probe on filters that contain denatured, immobilized plasmid DNA. No differences were observed in the transcriptional rate of MxA in the two different cellular milieu (Fig. 4). There were also no differences in the transcriptional rates of $\beta_{2^{-}}$ microglobulin and glyceraldehyde-3-phosphate dehydrogenase (GAPDH). These results suggest that the differential regulation of MxA in FA-C cells is primarily posttranscriptional.

$M x A$ promoter is not a direct target of FAC. While the above results implicate a posttranscriptional mechanism for the differential regulation of $\mathrm{MxA}$, a dual regulatory mechanism consisting of both transcriptional and posttranscriptional regulation cannot be excluded. Given that FAC is primarily cytoplasmic, several potential scenarios can be envisioned that may contribute to the transcriptional regulation of target genes. It is possible that a small amount of FAC protein may enter the nucleus and affect gene expression directly by interaction with the MxA promoter. Alternately, FAC may affect gene expression indirectly by either protein interactions with spatially-regulated transcription factors or proteins that affect mRNA stability. To evaluate these possibilities, the MxA promoter (Fig. $5 A$; references 34 and 35) was cloned into a promoterless expression plasmid encoding luciferase and transfected into COS-1 cells with or without expression plasmids encoding FAC. Coexpression of either wild-type FAC or an allele containing a deleterious missense mutation (L554P) failed to suppress the baseline luciferase activity of this promoter (Fig. $5 \mathrm{~B}$ ). Transfection of the MxA promoter construct into
HSC536 and HSC536-FAC lymphoblasts also failed to reveal any differences in promoter activity (data not shown). These results demonstrate that the MxA promoter is not a direct target of FAC.

$M x A$ activation is independent of STAT status. Because STAT proteins play critical roles in gene regulation initiated by IFN signaling, we also assessed whether the expression, activation or DNA-binding of STAT isoforms are different in
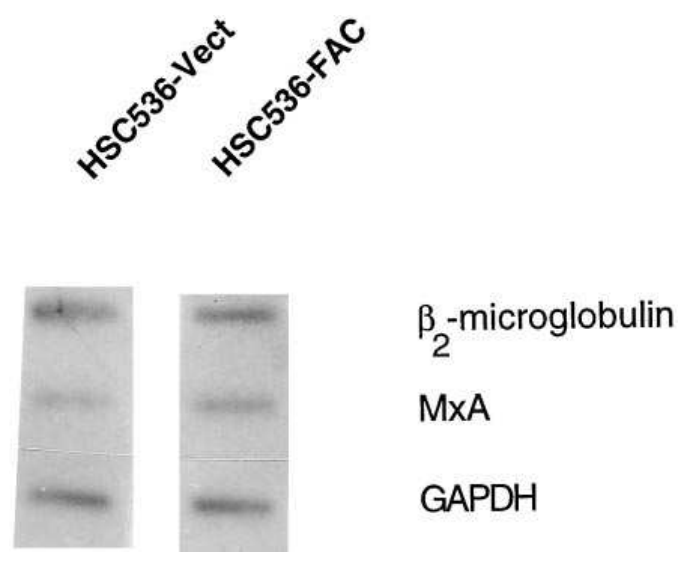

Figure 4. Similar rates of transcription in parental and complemented FA-C cells. The transcriptional activity of the MxA gene in parental and complemented FA-C lymphoblastoid cells was compared by nuclear run-on analysis. Equal quantities of plasmid DNA containing the indicated inserts were immobilized on filters and probed with radiolabeled nuclear RNA. 
A

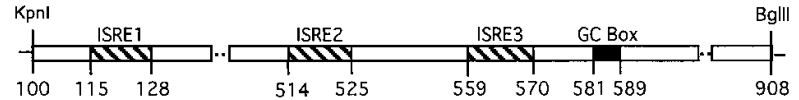

B

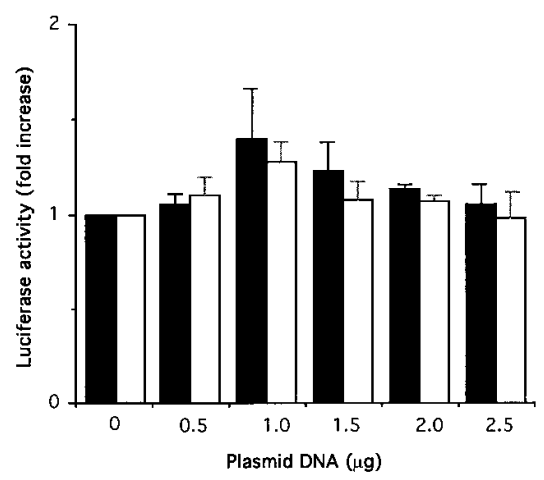

Figure 5. The MxA promoter is not a direct target of FAC. $(A)$ Schematic representation of the MxA promoter showing consensus binding sites for STATs. Numbers below the diagram show the base locations in the MxA promoter. To facilitate subcloning, KpnI and BglII sites were added during PCR amplification. (B) Activity of the MxA promoter in the presence of wild-type (black columns) and mutant (white columns) FAC isoforms. COS-1 cells were cotransfected with the MxA promoter fused to the reporter gene luciferase in the vector pXP2 as well as expression constructs encoding FAC isoforms and $\beta$-galactosidase. The luciferase activity in cell lysates was normalized for $\beta$-galactosidase activity. For dose-response studies, different quantities of plasmid DNA encoding FAC isoforms were used, as indicated. The mean and SEM are shown.

parental and complemented FA-C cells by a number of different assays. First, steady-state levels of STAT1 (Figs. $2 B$ and 3 $B$ ) as well as STAT2 and STAT3 (data not shown) analyzed by immunoblotting showed no differences in the overall expression levels of these proteins. Second, using nuclear extracts from HSC536 parental and FAC-complemented cells, we found no differences in the activation and DNA-binding profile of STATs and STAT-associated proteins by mobility-shift assays (data not shown). Finally, using sequential immunoprecipitation with anti-FAC antibodies and immunoblotting with anti-STAT antibodies from lysates of transfected COS-1 cells and HeLa cells, we failed to detect interactions between FAC and STATs 1, 2, or 3 under relatively mild binding conditions (e.g., $50 \mathrm{mM} \mathrm{NaCl}, 0.1 \%$ Triton X-100; data not shown), which have been used by us previously to detect interactions with other FAC-binding proteins (15; Youssoufian, H., T. Hoshino, J.M. Liu, P. Joseph, and A.K. Jaiswal, manuscript submitted for publication). Thus, MxA induction in FA group C cells appears to be independent of the expression or activation of STATs 1, 2, and 3. A direct interaction between FAC and STATs is also not supported by these studies.

Phenotypic effects of MxA overexpression. These studies demonstrate that MxA is downstream of FAC. Because MMC sensitivity and apoptosis are also consequences of FAC deficiency, it is possible that MxA overexpression can lead directly to these phenotypic effects and thus constitute a linear pathway of pathogenesis. Alternately, the phenotypic features of FA may result from the activities of pathways that are inde- pendent of MxA overexpression. To distinguish between these possibilities, we transfected MxA into a non-FA cell line, Hep3B, and obtained low-level expression of $\mathrm{MxA}$ in a population of cells that were resistant to G418 (Fig. 3 B). We then isolated individual clones and evaluated their response to MMC. In general, it was difficult to isolate clones that showed high levels of MxA by this strategy, suggesting that ectopic overexpression of MxA may be toxic to these cells. However, two clones (Hep3B clone No. 8 and No. 11) showed relatively high MxA levels and were chosen for subsequent studies. Hep3B clone No. 8 was significantly more sensitive to the cytotoxic effects of MMC than the parental counterpart (Fig. 6). The average dose of MMC reducing the survival of these cells to $50 \%$ of control levels (EC50) was $12 \mathrm{nM}$, while the average EC50 of parental Hep3B cells to MMC was $60 \mathrm{nM}$. This result supports the linear-pathway model of FA pathogenesis.

These cells were also examined for the presence of apoptotic markers by two different assays. First, the TUNEL assay was performed using a commercial kit and fluorescence microscopy. A significantly greater proportion of the Hep3B clone No. 8 cells were apoptotic compared with the parental cells (Fig. $7 \mathrm{~A}$ ). Quantitation of five different fields per coverslip that had cell densities of $\sim 50 \%$ confluence revealed $14 \pm 3$ fluorescent cells per 100 cells for clone No. 8 and $0 \pm 0$ for parental Hep3B cells. Pretreatment with MMC for $24 \mathrm{~h}$ did not enhance the number of apoptotic cells (data not shown). Second, genomic DNA prepared from parental Hep3B, clone No. 8 and clone No. 11 was also examined for the presence of DNA laddering characteristic of apoptosis. Both clones overexpressing MxA showed a greater degree of ladder formation than the parental cells (Fig. 7 B). As with the TUNEL assay, the presence of MMC did not appear to enhance the extent of ladder formation. These results demonstrate that MxA overexpression is sufficient to induce apoptosis in Hep3B cells.

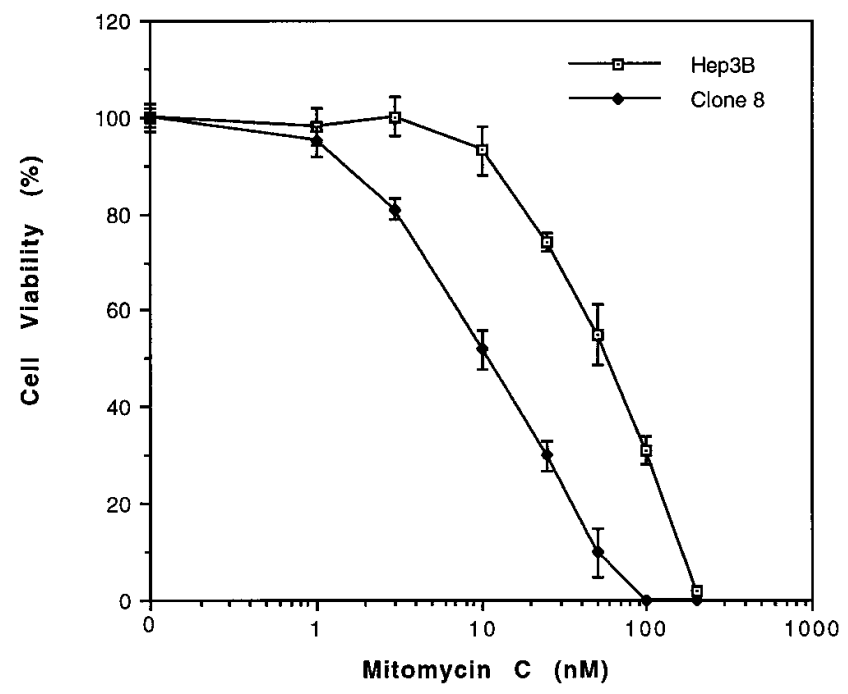

Figure 6. Induction of MMC sensitivity in Hep3B cells with MxA overexpression. Parental Hep3B and clone No. 8 overexpressing MxA were compared for their sensitivity to MMC. Cellular viability was assessed by trypan blue exclusion after continuous growth in $\mathrm{MMC}$ at the indicated doses for $6 \mathrm{~d}$. Experiments were performed in triplicate. The mean and SEM are shown. 
A

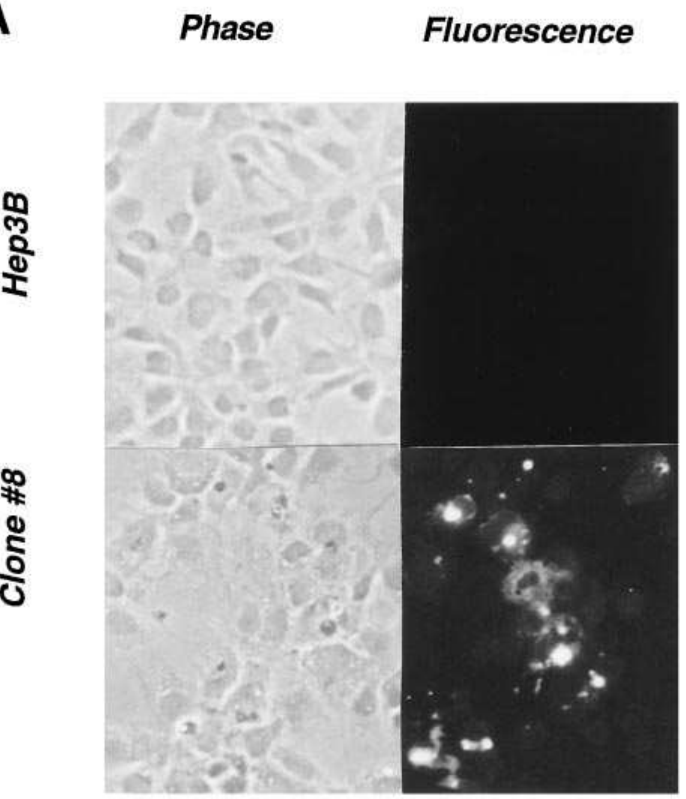

B

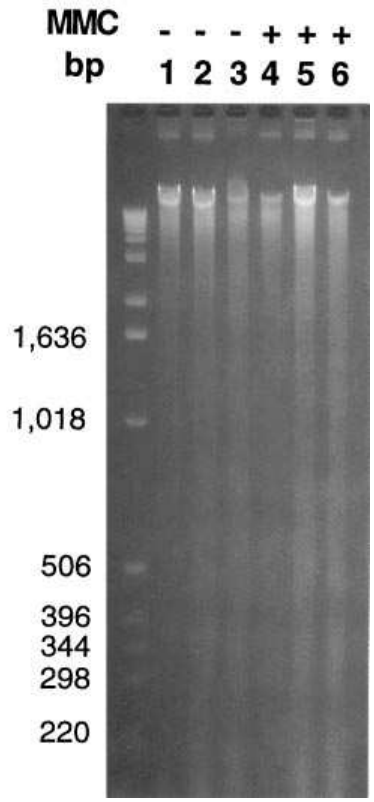

Figure 7. Induction of apoptosis by MxA. (A) In situ detection of apoptotic cells by fluorescence microscopy using the TUNEL assay. Parental Hep3B cells and a Hep3B transfected clone overexpressing MxA (clone No. 8) were grown on coverslips under identical conditions, fixed, and stained with fluorescein-dUTP for the detection of apoptotic cells. Phase contrast and fluorescent photomicrographs were obtained at a magnification of 100 . $(B)$ Increased DNA ladder formation in Hep3B cells overexpressing MxA with or without pretreatment with $100 \mathrm{nM}$ MMC for $24 \mathrm{~h}$, as indicated. Lanes 1 and 4, parental Hep3B cells; lanes 2 and 5, MxAexpressing Hep3B clone No. 8; lanes 3 and 6, MxA-expressing Hep3B clone No. 11. Molecular size markers are shown on the left lane.

\section{Discussion}

In this study, we demonstrate that MxA, an IFN-inducible gene, is overexpressed in FA cells of complementation groups $\mathrm{A}, \mathrm{B}, \mathrm{C}$, and $\mathrm{D}$ in the absence of exogenous stimulation by IFN. The overexpression of MxA is reversible by wild-type FAC, suggesting that FAC is a natural inhibitor of MxA in vivo. By contrast, several other IFN-inducible genes-including HLA human class I antigen, $\beta_{2}$-microglobulin, and IP10do not appear to be subject to regulation by FAC. Thus, the pathogenesis of FA may involve a constitutive, albeit selective, signaling by IFN. Our combined data on the altered expression of MxA demonstrates that the mechanism is primarily on a posttranscriptional level, although the precise mode of posttranscriptional control remains to be established.

Among the many cellular activities of IFNs is their ability to inhibit cellular proliferation in vivo and in culture (36). In fibroblasts stimulated by growth factors, $\alpha$ - or $\beta$-IFN delays the onset of DNA synthesis. In addition, IFNs antagonize the action of some positive growth factors, which may be particularly relevant to the growth of blood cell production where these polypeptides act as negative regulators $(37,38)$. Thus, high levels of IFNs may be expected to suppress hematopoiesis and have indeed been used clinically in myeloproliferative disorders where such activities would be desirable. IFNs have also been suspected to play a role in the hematopoietic failure of FA. The most compelling evidence comes from animal modeling attempts of FA. Targeted disruption of the murine fac gene recapitulates the chromosomal instability and other features of the human disorder $(39,40)$. It has been noted that the colonyforming capacity of murine progenitor cells declines progressively, and that low doses of $\gamma$-IFN profoundly inhibit the growth of erythroid and myeloid progenitors $(40,41)$. In addition, both human and murine primary hematopoietic progenitor cells are susceptible to apoptosis at lower doses of $\gamma$-IFN than their normal counterparts (41). It was, therefore, gratifying that our unbiased approach of mRNA differential display identified a gene that is associated with IFN signaling.
An increasing body of evidence also demonstrates that FA genes may have anti-apoptotic functions (41-44). Increased susceptibility to cross-link specific apoptosis in FA-C cells by a p53-independent mechanism has been described previously (43). In addition, FAC overexpression in either human or murine myeloid IL-3-dependent progenitor cells was also noted to delay the onset of apoptosis after withdrawal of the critical growth factor (44). Taken together, these results show that FAC is coupled to fundamental pathways that regulate cell death. In this study, our observations that MxA overexpression is coupled to apoptosis leads us to propose the following model (Fig. 8). Constitutive overexpression of MxA by IFNs or viral infection (i.e., exogenous stimuli) could result in gradual loss of stem cells from the bone marrow. Similarly, an intrinsic cellular defect (i.e., FAC and perhaps other FA gene mutations) could also lead to apoptosis and progressive cell loss. The inability to replace apoptotic cells efficiently may eventually lead to marrow aplasia. In principle, this mechanism could also operate in other cell types and may account for additional phenotypic features of FA. Although transgenic mice expressing high levels of the human MxA protein have been described and shown to be resistant to viral infections (45), the effect of MxA overexpression on blood cell formation was not analyzed, possibly because of inadequate expression

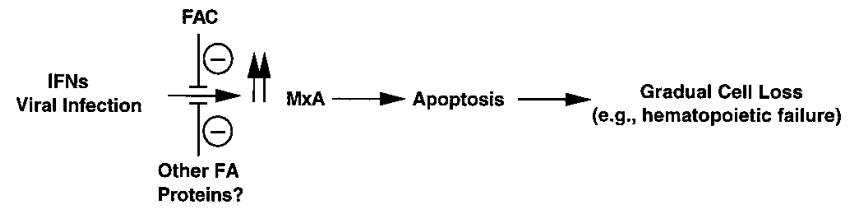

Figure 8. Hypothetical model of MxA dysregulation and its consequences. Constitutive overexpression of $\mathrm{MxA}$ by either exogenous stimuli (IFNs or viral infection) or an intrinsic deficiency (FAC and perhaps other FA gene mutations) could result in progressive loss of cells by apoptosis. In the case of the bone marrow, the loss of hematopoietic stem cells may eventually lead to bone marrow failure. 
of the transgene in these cells or to embryonic lethality. Hence, an evaluation of the in vivo effects of $\mathrm{MxA}$ on hematopoiesis may have to await the generation of more appropriate animal models.

A number of critical questions remain about the relevance of this novel pathway to the pathogenesis of FA. The observation that MxA is a GTPase raises the issue of in vivo targets for this enzyme, particularly those that are associated with known pathways of apoptosis. In addition, it is reasonable to suspect that an as yet unknown GTPase-associated protein could dampen or reverse the GTPase activity of MxA. The expression of the latter putative molecule may be particularly important for the modulation of disease severity in FA.

Finally, although controversial, resistance to infection by microorganisms has been invoked as a selective force in the maintenance of otherwise deleterious, mutant alleles in heterozygotes (46). For example, certain forms of thalassemia, heterozygosity for the sickle cell mutation, and G6PD deficiency are all thought to confer protection against malaria (46, 47). It has also been postulated that heterozygotes for cystic fibrosis may have a selective advantage for resistance to cholera (48) as well as to noninfectious or to other potentially-infectious disorders, such as bronchial asthma (49). Similarly, it may be worth speculating that in asymptomatic carriers (or possibly in affected homozygotes or compound heterozygotes) FA mutations could confer protection against respiratory infections caused by influenza or related viruses.

\section{Acknowledgments}

We wish to thank M.A. Horisberger for contributing a sample of the MxA antibody, M. Grompe for the PD20 cells, A.D. Auerbach for the LCL171 cells, and D. Tenen for the luciferase expression vectors.

This study was supported by grants from the National Institutes of Health (HL52138), the Leukemia Society of America, and the Lawrence Family Fund.

\section{References}

1. Fanconi, G. 1967. Familial panmyelocytopathy, Fanconi's anemia (FA). I. Clinical aspects. Semin. Hematol. 4:233-240.

2. Alter, B.P., and N.S. Young. 1993. The bone marrow failure syndromes. In Hematology of Infancy and Childhood. D.G. Nathan and F.A. Oski, editors. W.B. Saunders Company, Philadelphia. 216-316.

3. Liu, J.M., M. Buchwald, C.E. Walsh, and N.S. Young. 1994. Fanconi anemia and novel strategies for therapy. Blood. 84:3995-4007.

4. Duckworth-Rysiecki, G., K. Cornish, C.A. Clarke, and M. Buchwald. 1985. Identification of two complementation groups in Fanconi anemia. Somatic. Cell Mol. Genet. 11:35-41.

5. Strathdee, C.A., A.M.V. Duncan, and M. Buchwald. 1992. Evidence for at least four Fanconi anaemia genes including FACC on chromosome 9. Nat. Genet. 1:196-198.

6. Joenje, H., J.R. Lo Ten Foe, A.B. Oostra, C.G.M. van Berkel, M.A. Rooimans, T. Schroeder-Kurth, R.-D. Wegner, J.J.P. Gille, M. Buchwald, and F. Arwert. 1995. Classification of Fanconi anemia patients by complementation analysis: evidence for a fifth genetic subtype. Blood. 86:2156-2160.

7. Pronk, J.C., R.A. Gibson, A. Savoia, M. Wijker, N.V. Morgan, S. Melchionda, D. Ford, S. Temtamy, J.J. Ortega, S. Jansen, et al. 1995. Localisation of the Fanconi anaemia complementation group A gene to chromosome 16q24.3. Nat. Genet. 11:338-340.

8. Whitney, M., M. Thayer, C. Reifsteck, S. Olson, L. Smith, P.M. Jakobs, R. Leach, S. Naylor, H. Joenje, and M. Grompe. 1995. Microcell mediated chromosome transfer maps the Fanconi anaemia group D gene on chromosome 3p. Nat. Genet. 11:341-343.

9. Strathdee, C.A., H. Gavish, W.R. Shannon, and M. Buchwald. 1992. Cloning of cDNAs for Fanconi's anaemia by functional complementation. $\mathrm{Na}$ ture. 356:763-767.

10. Lo Ten Foe, J.R., M.A. Rooimans, L. Bosnoyan-Collins, N. Alon, M. Wijker, L. Parker, J. Lightfoot, M. Carreau, D.F. Callen, A. Savoia, et al. 1996.
Expression cloning of a cDNA for the major Fanconi anemia gene, FAA. Nat. Genet. 14:320-323.

11. The Fanconi Anaemia/Breast Cancer Consortium. 1996. Positional cloning of the Fanconi anaemia group A gene. Nat. Genet. 14:324-328.

12. Yamashita, T., D.L. Barber, Y. Zhu, N. Wu, and A.D. D'Andrea. 1994 The Fanconi anemia polypeptide, FACC, is localized to the cytoplasm. Proc. Natl. Acad. Sci. USA. 91:6712-6716.

13. Youssoufian, H. 1994. Localization of Fanconi anemia C protein to the cytoplasm of mammalian cells. Proc. Natl. Acad. Sci. USA. 91:7975-7979.

14. Youssoufian, H. 1996. Cytoplasmic localization of FAC is essential for the correction of a prerepair defect in Fanconi anemia group C cells. J. Clin. Invest. 97:2003-2010.

15. Youssoufian, H., A.D. Auerbach, P.C. Verlander, V. Steimle, and B. Mach. 1995. Identification of cytosolic proteins that bind to the Fanconi anemia complementation group C polypeptide in vitro. J. Biol. Chem. 270:9876-9882.

16. Liang, P., and A.B. Pardee. 1992. Differential display of eukaryotic messenger RNA by means of the polymerase chain reaction. Science. 257:967-971.

17. Horisberger, M.A., P. Staeheli, and O. Haller. 1983. Interferon induces a unique protein in mouse cells bearing a gene for resistance to influenza virus. Proc. Natl. Acad. Sci. USA. 80:1910-1914.

18. Aebi, M., J. Fah, N. Hurt, C.E. Samuel, D. Thomas, L. Bazzigher, J. Pavlovic, O. Haller, and P. Staeheli. 1989. cDNA structures and regulation of two interferon-induced human Mx proteins. Mol. Cell. Biol. 9:5062-5072.

19. Horisberger, M.A., G.K. McMaster, H. Zeller, M.G. Wathelet, J. Dellis, and J. Content. 1990. Cloning and sequence analyses of cDNAs for interferonand virus-induced human Mx proteins reveal that they contain putative guanine nucleotide-binding sites: functional study of the corresponding gene promoter. J. Virol. 64:1171-1181

20. Horisberger, M.A. 1992. Interferon-induced human protein MxA is a GTPase which binds transiently to cellular proteins. J. Virol. 66:4705-4709.

21. Dreiding, P., P. Staeheli, and O. Haller. 1985. Interferon-induced protein $\mathrm{Mx}$ accumulates in nuclei of mouse cells expressing resistance to influenza virus. Virology. 140:192-196.

22. Meier, E., J. Fah, M.S. Grob, R. End, P. Staeheli, and O. Haller. 1988. A family of interferon-induced Mx-related mRNAs encodes cytoplasmic and nuclear proteins in rat cells. J. Virol. 62:2386-2393.

23. Staehli, P., and J.G. Sutcliffe. 1988. Identification of a second interferonregulated murine Mx gene. Mol. Cell. Biol. 8:4524-4528.

24. Staehli, P., Y.-X. Yu, R. Grob, and O. Haller. 1989. Double-stranded RNA inducible fish gene homologous to the murine influenza virus resistance gene Mx. Mol. Cell. Biol. 9:3117-3121.

25. Rothman, J.H., C.K. Raymond, T. Gilbert, P.J. O'Hara, and T.H Stevens. 1990. A putative GTP binding protein homologous to interferoninducible $\mathrm{Mx}$ proteins performs an essential function in yeast protein sorting. Cell. 61:1063-1074.

26. Krug, R.M., M. Shaw, B. Broni, G. Shapiro, and O. Haller. 1985. Inhibition of influenza viral mRNA synthesis in cells expressing the interferon-induced Mx gene product. J. Virol. 56:201-206.

27. Staehli, P., O. Haller, W. Boll, J. Lindenmann, and C. Weissmann. 1986. Mx protein: constitutive expression in $3 \mathrm{~T} 3$ cells transformed with cloned $\mathrm{Mx}$ cDNA confers selective resistance to influenza virus. Cell. 44:147-158.

28. Staehli, P., and O. Haller. 1987. Interferon-induced Mx protein: a mediator of cellular resistance to influenza virus. Interferon. 8:1-23.

29. Arnheiter, H., and O. Haller. 1988. Antiviral state against influenza virus neutralized by microinjection of antibodies to interferon-induced Mx proteins. EMBO (Eur. Mol. Biol. Organ.) J. 7:1315-1320.

30. Pavlovic, J., T. Zurcher, O. Haller, and P. Staeheli. 1990. Resistance to influenza virus and vesicular stomatitis virus conferred by expression of human MxA protein. J. Virol. 64:3370-3375.

31. Ausubel, F.M., R. Brent, R.E. Kingston, D.D. Moore, J.G. Seidman, J.A. Smith, and K. Struhl, editors. 1994. Current Protocols in Molecular Biology. Greene Publishing Associates and John Wiley \& Sons, New York.

32. Sambrook, J., E.F. Fritsch, and T. Maniatis. 1989. Molecular Cloning: A Laboratory Manual, Second Ed. Cold Spring Harbor Press, Cold Spring Harbor, NY.

33. Ronni, T., K. Melen, A. Malygin, and I. Julkunen. 1993. Control of IFNinducible MxA gene expression in human cells. J. Immunol. 150:1715-1726.

34. Chang, K.C., E. Hansen, L. Foroni, L. Lida, and G. Goldpink. 1991. Molecular and functional analysis of the virus- and interferon-inducible human MxA promoter. Arch. Virol. 117:1-15.

35. Fu, X.-Y., C. Schindler, T. Improta, R. Aebersold, and J.E. Darnell. 1992. The proteins of ISGF-3, the interferon $\alpha$-induced transcriptional activator, define a gene family involved in signal transduction. Proc. Natl. Acad. Sci. USA. 89:7840-7843.

36. Petska, S., J.A. Langer, K.C. Zoon, and C.E. Samuel. 1987. Interferons and their actions. Annu. Rev. Biochem. 56:727-777.

37. Raefsky, E.L., L.C. Platanias, N.C. Zoumbos, and N.S. Young. 1985 Studies of interferon as a regulator of hematopoietic cell proliferation. J. Immunol. 135:2507-2512.

38. Wang, C.Q., K.B. Udupa, and D.A. Lipshitz. 1995. Interferon- $\gamma$ exerts its negative regulatory effect primarily on the earliest stages of murine erythroid progenitor cell development. J. Cell. Physiol. 162:134-138. 
39. Chen, M., D.J. Tomkins, W. Auerbach, C. McKerlie, H. Youssoufian, L. Liu, O. Gan, M. Carreau, A. Auerbach, T. Groves, et al. 1996. Inactivation of Fac in mice produces inducible chromosomal instability and reduced fertility reminiscent of Fanconi anaemia. Nat. Genet. 12:448-451.

40. Whitney, M.A., G. Royle, M.J. Low, M.A. Kelly, M.K. Axthelm, C. Reifsteck, S. Olson, R.E. Braun, M.C. Heinrich, R.K. Rathbun, G.C. Bagby, and M. Grompe. 1996. Germ cell defects and hematopoietic hypersensitivity to $\gamma$-interferon in mice with a targeted disruption of the Fanconi anemia $\mathrm{C}$ gene. Blood. 88:49-58

41. Rathbun, R.K., G.R. Faulkner, M.H. Ostroski, T.A. Christianson, G. Hughes, G. Jones, R. Cahn, R. Maziarz, G. Royle, W. Keeble, et al. 1997. Inactivation of the Fanconi anemia group $\mathrm{C}$ gene augments interferon-gamma-induced apoptotic responses in hematopoietic cells. Blood. 90:974-985.

42. Kruyt, F.A.E., L.M. Dijkmans, T.K. van den Berg, and H. Joenje. 1996. Fanconi anemia genes act to suppress a cross-linker-inducible p53-independent apoptosis pathway in lymphoblastoid cell lines. Blood. 87:938-948.

43. Marathi, U.K., S.R. Howell, R.A. Ashmun, and T.P. Brent. 1996. The Fanconi anemia complementation group C protein corrects DNA interstrand cross-link-specific apoptosis in HSC536N cells. Blood. 88:2298-2305.

44. Cumming, R.C., J.M. Liu, H. Youssoufian, and M. Buchwald. 1996. Suppression of apoptosis in hematopoietic factor-dependent progenitor cell lines by expression of the FAC gene. Blood. 88:4558-4567.

45. Pavlovic, J., H.A. Arzet, H.P. Hefti, M. Frese, D. Rost, B. Ernst, E. Kolb, P. Staeheli, and O. Haller. 1995. Enhanced virus resistance of transgenic mice expressing the human MxA protein. J. Virol. 69:4506-4510.

46. Weatherall, D.J. 1996. Host genetics and infectious disease. Parasitology. 112(Suppl.):S23-S29.

47. Miller, L.H. 1996. Malaria: protective selective pressure. Nature. 383: 480-481.

48. Gabriel, S.E., K.N. Brigman, B.H. Koller, R.C. Boucher, and M.J. Stutts. 1994. Cystic fibrosis heterozygote resistance to cholera toxin in the cystic fibrosis mouse model. Science. 266:107-109.

49. Schroeder, S.A., D.M. Gaughan, and M. Swift. 1995. Protection against bronchial asthma by CFTR delta F508 mutation: a heterozygote advantage in cystic fibrosis. Nat. Med. 1:703-705. 